\title{
Identifying Needy Students for University-Industry Snapfeed Program
}

\author{
Norfadzilah Abd Razak¹ Rugayah Hashim², Zaidi Mohd Aminuddin¹, Zuraidah Ismail1, \\ ${ }^{1}$ Faculty of Business \& Management, 2 Research \& Innovation Division, \\ Universiti Teknologi MARA Cawangan Selangor, Puncak Alam, Selangor, Malaysia \\ norfadzilah0438@gmail.com, guy73106@yahoo.com, pmzaidi@yahoo.com.my, zuraisma69@gmail.com \\ Tel: +6013-3852288
}

\begin{abstract}
This paper aims to provide empirical evidence on the university students' nutritional habits and peer pressure on food purchases. In addition, the motivations for the study were the media highlights on poverty among public university students that led to hunger. A survey was conducted with a sample size of 1,000 students; the response rate was $80 \%$. The findings revealed the dietary patterns from money spent on food. Cross-tabulation between family income and the number of daily meals per day showed that students coming from a lowincome background have satisfactory nutritional habits, but lack of money meant lesser meals or food insecurity. Hence, a snapfeed program for low-income student to assist with daily food intake was suggested.
\end{abstract}

Keywords: Needy students; poverty; dietary habits; food insecurity

eISSN: 2398-4287 @ 2019. The Authors. Published for AMER ABRA cE-Bs by e-International Publishing House, Ltd., UK. This is an open access article under the CC BYNC-ND license (http://creativecommons.org/licenses/by-nc-nd/4.0/). Peer-review under responsibility of AMER (Association of Malaysian Environment-Behaviour Researchers), ABRA (Association of Behavioural Researchers on Asians) and cE-Bs (Centre for Environment-Behaviour Studies), Faculty of Architecture, Planning \& Surveying, Universiti Teknologi MARA, Malaysia.

DOI: https://doi.org/10.21834/e-bpj.v4i12.1900

\subsection{Introduction}

As the world turns and time changes, food security, or insecurity has now become every government's priority as per the United Nation's Sustainable Development Goals (UN, 2016). In tandem with the increase in population globally, feeding the poor and communities with disabilities have become a perennial problem. At the micro-level, families from low-income groups realized the importance of education as the stepping stone to a better quality of life and well-being. Hence, their children seeking tertiary education were enrolled at various universities for that purpose. However, in doing so, money and food have again been the cause for concern. Lately, for Malaysia, the issue has been brought to the university's administration that some students were not eating well because of insufficient funds (Abu Bakar, Ismail, Sidek, \& Rahman, 2019; Ramlee, Ali, Zalbahar, Wahab, \& Jaafar, 2019). The literature reviewed evidenced similar issues in other universities throughout the world (El Zein et al., 2019; Ukegbu, Nwofia, Ndudiri, Uwakwe, \& Uwaegbute, 2019; Wooten, Spence, Colby, \& Steeves, 2019). For Malaysia, the media has highlighted that students at public universities do not have enough money to buy food. Some have gone to the extreme to fast daily, while others have relied on friends to share their food. Upon that realization, the Economics Department of the Faculty of Business and Management, Universiti Teknologi MARA, Cawangan Selangor, Puncak Alam Campus, has taken the initiative to survey a segment of the student population for empirical evidence to this problem. Although these data can quickly be drawn from the Student Affairs Department, the actual cases of poverty among university students can be traced through their eating habits.

Moreover, during the Pre-JAF (Faculty Academic Committee) meeting, feedbacks were received from several lecturers who reported that some students have to work to support their study. Some of these students have good academic standing at the diploma level. Unfortunately, due to financial constraints as they were from low-income families, they have to work to pay for their studies, and this situation has led to their low academic performance. There were cases where students approached their advisors to discuss similar

eISSN: 2398-4287 (C) 2019. The Authors. Published for AMER ABRA cE-Bs by e-International Publishing House, Ltd., UK. This is an open access article under the CC BYNC-ND license (http://creativecommons.org/licenses/by-nc-nd/4.0/). Peer-review under responsibility of AMER (Association of Malaysian Environment-Behaviour Researchers), ABRA (Association of Behavioural Researchers on Asians) and cE-Bs (Centre for Environment-Behaviour Studies), Faculty of Architecture, Planning \& Surveying, Universiti Teknologi MARA, Malaysia. DOI: https://doi.org/10.21834/e-bpj.v4i12.1900 
situations, and these were the red flags that allowed the Coordinator in charge to track these students. However, the main problem comes from those who are poor and not working to earn extra money for their expenditure, especially food. Literature has shown that the students' academic performance were negatively affected when they are financially strapped. Malnutrition has been shown to affect students' health adversely, hence the poor grades.

Consequently, the Economics Department of the Faculty of Business and Management, Universiti Teknologi MARA, Cawangan Selangor, Puncak Alam Campus, has taken the initiative to survey 1000 students for empirical evidence to this problem. The majority of the respondents who participated in this survey stayed in college $(n=735)$, followed by non-residents $(n=86)$, and only 37 of students were staying with their families. From ad-hoc conversations with the students, most of the students admitted that any monies that they have were spent on food, stationery, assignments, and projects while the bulk is on food and drinks. For those who have opted to stay off-campus, the money goes to rent and transport. Other side spending included phone bills and utilities. It has also been brought to the academic management office's attention that some of the students worked to send money home as their parents may be incapable of holding a job due to health complications.

\subsection{Literature Review}

In recent years, the issues of food security (or insecurity) have gained momentum and the attention of the world's communities. It is still an ongoing debate worldwide, as it is a multi-dimensional and complex matter (Rush, 2019). In the UN's sustainable development goal (SDG \#2), the aim is to" end hunger, achieve food security and improved nutrition and promote sustainable agriculture" (UN, 2016). The target of the goal is to end hunger and ensure access by all people, in particular, the poor and people in vulnerable situations, including infants, to safe, nutritious and sufficient food all year round (ibid). However, the experience of global food crises has escalated because of global warming and climate change (Ngarava, Zhou, Ayuk, \& Tatsvarei, 2019). Also, the disruption of development, physiological, and psychological differences have been identified to be the cause of food insecurity (Feingold et al., 2019). People are struggling to survive to have proper food on the table. In doing so, food security encompasses food with sufficient nutrition, affordability and, physical and economical to meet their needs and food preferences (Roggio, 2019). Thus, the people are easily affected by physical and mental health problems, difficulty in deciding on their life choices (Azdie, 2019), including university students (Martinez, Grandner, Nazmi, Canedo, \& Ritchie, 2019).

\subsection{Food Security Issues}

In recent, the issues of food security have gained attention in most of the world's communities. It is still an ongoing debate worldwide, as it is a multi-dimensional and complex matter (Norhasmah, Zalilah \& Asnarulkhadi, 2010). In the sustainability development goal (SDG \#2), the aim is to" end hunger, achieve food security and improved nutrition and promote sustainable agriculture." The target of the goal is to end hunger and ensure access by all people, in particular, the poor and people in vulnerable situations, including infants, to safe, nutritious and sufficient food all year round. However, the experience of the global food crisis becomes critical. The disruption of development, physiological, and psychological changes (Alaimo, Olson \& Frongillo, 2002) have been identified to cause food insecurity. In many disadvantaged communities, people are struggling to survive. Impoverished societies' priority is to have food. In ensuring adequate food for daily intake, proper diet should be sufficient, nutritional, affordable, fulfills physical and economic needs in food preferences. When the opposite occurs, people are easily affected by physical and mental health problems with difficulty in deciding on their life choices (Martinez et al., 2019).

On the flip side of the coin, environmentally sustainable behaviors have focused on the impact of psychological factors relative to satisfaction (Ertz \& Sarigollu, 2019). When associating these elements to the scope of university students, empirical evidence is required. Hence, the conduct of the study. Nonetheless, the argument on food insecurity affecting students from disadvantaged backgrounds remains the crux of the matter.

\subsection{University students and poverty}

To reiterate, with the population boom, the number of individuals enrolled at universities has also increased based on meritocracy. However, the financial capability of some students was not considered for specific universities. Literature has shown that meal programs for schools in the United States are essential for reducing food insecurity (Turner, Guthrie, \& Ralston, 2019). Bring back the issue of students from impoverished backgrounds, the relevant ministry and the university administrators have significantly increased the efforts to ensure that the students do not drop out of school. Although some of the students do receive financial aid, the amount is usually insufficient to cover daily food expenses. One example of food assistance for these students provided by most universities is the food bank. The food banks are typically located at buildings that are guaranteed their presence, for instance, the health center, the students' affairs department, and the academic affairs department.

Nevertheless, the growing awareness that university students, particularly undergraduates who are food insecure, remains a perennial issue (Broton, Weaver, \& Mai, 2018). Similarly, for universities in Malaysia, food insecurity because of poverty potentially undermines investments in higher education and hinders upward social mobility (ibid). As such, the research project and this paper come at a convenient time in showcasing the undergraduates' food insecurity because of poverty.

\subsection{Extent of University Students' Nutritional Habits to Food Insecurity}

The extent of undergraduates' food insecurity to nutritional habits is significant (Broton et al., 2018). Broton et al. (2018) reported that students who grew up in food-secure homes were significantly more likely to report the lowest level of food security, or in layman's 
terms, hunger. As undergraduates, lack of time and money resulted in food insecurity. Although the students rely on friends or family for support, the eligibility restrictions limited the social safety net, that is, getting food subsidies from the relevant entities. In this study's case, the number of students who decided to drop out of their final semester undergraduate program was not because of food security. Instead, it was due to their inability to pay the tuition fees. For their daily existence, food intake depends on what is available. The cheapest alternative is the instant noodle, though some were fortunate enough to have caring dormmates who share their meals.

On the other hand, Bruening, van Woerden, Todd, and Laska (2018) found that compared with secure food students, food-insecure students are more likely to be at risk for poor health and report lower fruit and vegetable consumption. Fortunately for this investigation, the survey questions were related to healthy food intake; that is, students' food choices of fruit and vegetables. At Universiti Teknologi MARA, Selangor Branch (UCS), food stalls are serving local dishes that fulfill the students' daily food intake. However, food choices may not be healthy, as pointed out by Bruening et al. (2018), where campus food environments can contribute to poor eating behaviors, limited hours of operation, high prices at healthy dining eateries, and limited access to grocery stores. The researchers' monitoring of food stalls on campus evidenced several stores selling various cut fruit, which showed that UCS is concerned that students eat healthy every day. Then again, the choices of food that students pick depends on their appetite for that day.

\subsection{Methodology}

This study surveyed 1000 students of Faculty of Business and Management, Universiti Teknologi MARA, Cawangan Selangor, Puncak Alam Campus. The response return rates were $80 \%$, which total of 861 had participated in the survey, and 20 percent have not completed the study and not accounted in this study. The items for the review were more concentrated on the routine spending and dietary pattern such as "How often do you eat the following meals breakfast, lunch, and dinner?", "On average, how much do you spend on the following meals every day- Breakfast, lunch, and dinner." The data collection has further been analyzed using descriptive analysis, including cross-tabulation for further findings.

\subsection{Findings and Discussion}

The findings revealed the dietary patterns of university students at the Puncak Alam campus. In the cross-tabulation between family's income and the number of daily meals per day, the evidence of students coming from the bottom 40 (B40) or with the family income of below 3,000 Malaysian Ringgit (approximately USD 730 per month) is significant. Although there are data of needy students registered with the Students Affairs Department, the extent of financial disabilities evoked from the findings indicated a higher number of students in the B40 category. The number of siblings too, played an important part in family economics.

Table 1. Students' Daily Intake for Breakfast, Lunch, and Dinner

\begin{tabular}{|l|c|c|c|c|}
\hline Daily Take & 0-1 times a week & $2-3$ times a week & $4-5$ times a week & $6-7$ times a week \\
\hline Breakfast & $246(28.6 \%)$ & $318(36.9 \%)$ & $167(19.4 \%)$ & $114(13.2 \%)$ \\
\hline Lunch & $54(6.3 \%)$ & $130(15.1 \%)$ & $230(26.7 \%$ & $438(50.9 \%)$ \\
\hline Dinner & $93(10.8 \%)$ & $200(23.2 \%)$ & $265(30.8 \%)$ & $277(32.2 \%)$ \\
\hline
\end{tabular}

From Table 1, the findings revealed the pattern of spending by the students for breakfast, lunch, and dinner. From Table 1, during breakfast, 525 (61\%) students spend less than RM 2, a total of 272 (31.6\%) students spend between RM3 to RM 5, and only 15 (1.7\%) of students spend for more than RM 9 and more than RM12. Students pay less for breakfast, and some students have enough for breakfast. For lunch, the highest spending of 435 (50.5\%) of students was between RM3 to RM5, followed by 320 (37.2\%) of students spend between RM6 to RM 8. Only 58 (16.7\%) of students spend their lunch between RM 9 to RM 12, and a total of 16 (1.9\%) spend more than RM12. The finding also found that a total of $17(2 \%)$ of students spend less than RM2 for their lunch. From the analysis, this study can be explained that most of the students willing and enough to pay for their lunch. On the other hand, a total of $93(10.8 \%)$ has dinner only one time a week. However, $405(47 \%)$ of students will spend about RM3 to RM5 for dinner, $245(28.5 \%)$ spend about RM6 to RM8. Also, $63(7.3 \%)$ students were willing to pay about RM 9 to RM12, and 20 (2.3\%) students spend more than RM12. This result indicated that students wisely spend their money to have dinner.

Table 2. Students' Spending Pattern

\begin{tabular}{|l|c|c|c|c|c|}
\hline Spend & RM 0 - RM 2 & RM 3 - RM 5 & RM 6 - RM 8 & RM 9 - RM 12 & More than RM12 \\
\hline Breakfast & $525(61 \%)$ & $272(31.6)$ & $28(12 \%)$ & $12(1.4 \%)$ & $3(0.3 \%)$ \\
\hline Lunch & $17(2 \%)$ & $435(50.5)$ & $320(37.2)$ & $58(6.7 \%)$ & $16(1.9 \%)$ \\
\hline Dinner & $97(11.3 \%)$ & $405(47.0 \%)$ & $245(28.5 \%)$ & $63(7.3 \%)$ & $20(2.3 \%)$ \\
\hline
\end{tabular}


On top of the discussion, the dietary pattern of the students was significantly influenced by the household income and numbers of a sibling, as shown in Table 3. The average number of students $(n=168)$ was from families with household earnings between RM1500 to RM3000. Additional information, the average number of siblings in a family was $3-4$ siblings $(n=131)$, followed by $5-6$ siblings $(n=107)$, and only 40 of the students have more than seven siblings. Moreover, there was a total of 23 students have between 1-2 siblings, and an only child was 6 . The crosstab analysis in Table 2 revealed that a higher number of students in the B40 category. These categories have spent more on the high number of siblings compared to the family who does not have siblings. Students who are the only child in the family have more money to spend in a day.

Table 3. Cross-Tabulation of Household Income and Numbers of Siblings

\begin{tabular}{|l|c|c|c|c|c|}
\hline \multicolumn{1}{|c|}{ Several siblings in your family? } & RM100-1,500 & $\begin{array}{c}\text { RM1,500- } \\
3,000\end{array}$ & $\begin{array}{c}\text { RM3,001-5,000 } \\
\text { RM3,001- } \\
5,000\end{array}$ & $\begin{array}{c}\text { RM5,001- } \\
8,000 \\
\text { RM8,001 }\end{array}$ & \begin{tabular}{c} 
More than \\
\hline $1-2$
\end{tabular} \\
\hline $3-4$ & 3 & 8 & 0 & 27 & 23 \\
\hline $5-6$ & 29 & 34 & 1 & 25 & 13 \\
\hline More than seven siblings & 22 & 30 & 0 & 7 & 2 \\
\hline Only child & 0 & 4 & 0 & 1 & 0 \\
\hline Total & 83 & 84 & 1 & 67 & 38 \\
\hline
\end{tabular}

The finding further revealed that the dietary pattern of students are having their meals for breakfast, lunch, and dinner. The highest frequencies of the breakfast taken by students were 2 to 3 times a week, with a total of $318(36.9 \%)$, followed by 6 to 7 times a week by $114(13.2 \%)$ of students. This result indicates that most of the students always take early breakfast before coming to class. Students only get the bread or sandwich, and in between breakfast and lunch, they have biscuits and cookies. They spend their breakfast at college and cafeteria. The price offers at those places is affordable and appropriate for students. However, there are about $246(28.6 \%)$ of students skipped or at least one time to take breakfast. The possible reason for them to skip breakfast is due to limit of time rush to early morning class and only have lunch for a day.

Moreover, the analysis reveals the dietary pattern for lunch. Most of the students regularly take their lunch 6 to 7 times a week. They prefer the cafeteria near their classes. Students usually take rice as main dishes followed by noodles and bread. However, there are also $54(6.3 \%)$ of students only take one time a week for their lunch. This indicated that the group of students allocates their time and money for dinner.

On the other hand, students do not skip their dinner. They consistently take dinner every 6 to 7 times once in a week with the highest frequency of $277(32.2 \%)$ students, followed by 4 to 5 times a week was $265(30.8 \%)$. However, some students take less than 2 to 3 times a week, with a total of $200(23.2 \%)$ students and only $93(10.8 \%)$ do not take dinner.

The implications from the findings evidenced a higher number of needy students who do not have enough money for proper, daily food intake. Hence the Snapfeed Program is suggested. The Snapfeed Program has identified students from low-income background through data obtained from the Students Affairs Department and through solicitations from the dorm mates, as evidenced by the survey feedbacks. The confirmation of the recipients for the Snapfeed Program, these students rely on the kindness of the colleagues and dorm mates to share food. In the Students Affairs Department's list, students who have been listed in the B40 category are given financial assistance, but their spending habits led to less allocation for food. An alternative aid to this problem is the Snapfeed Program, where students are given a personal card loaded with MYR200 per month. Using a customized identification system, only purchases for food and drinks are allowed. The Snapfeed Program's security chip in the card will only allow these purchases at pre-identified vendors on campus. That way, the students will not misspend the fund given to them.

The findings similarly support that food insecurity among college students is highly prevalent, resulting in a significant public health problem that adversely affects health outcomes (Bruening et al., 2018). The findings from this study suggest that it is essential for UCS administrators, specifically the Students Affairs Department, to rigorously identify students with financial woes as food insecurity is closely associated with unhealthy students. Another option to request monthly students' visits to the university's health center and identifying malnourished undergraduates. As pointed out in the literature, when students are struggling, they may be coping with several challenges simultaneously; thus, multifaceted intervention strategies addressing a variety of issues may be needed (ibid). As the number of student intake increases for UiTM, the diverse needs of the millennials have shown varying needs. To reiterate Bruening et al.'s (2018) suggestion, university public health officials should work with administrators to systematically screen for food insecurity. "More public health research is needed on how to prevent and address food insecurity on and before students come to university." (ibid). The findings from this study are significant in ensuring that UiTM's needy students' academic performances are not jeopardized by malnutrition.

\subsection{Conclusion and Recommendation}

The study was aimed at determining the students from impoverished backgrounds concerning their food intake. Hence, to conclude, the findings revealed that the students from food-insecure families are not eating healthy meals. The choice of food that is high on the list 
for their low price is instant noodles. The content of the noodles was not nutritionally advocated in the long term, daily intake. As a recommendation, students' daily intakes of meals have to be monitored and advised. When students visit the Health Center at UCS, the medical officer should inquire about the students' food intake. Although the Snapfeed Program may be valuable in assisting students with financial issues, their food intake must be of utmost importance. As shown from literature, the students' academic performances were strongly related to healthy eating.

\section{Acknowledgments}

We would like to acknowledge the Ministry of Education, Malaysia, for awarding the Fundamental Research Grant Scheme (FRGS 053/2017). We would also like to acknowledge Universiti Teknologi MARA, Selangor Branch, for the research management support.

\section{References}

Abu Bakar, W. A. M., Ismail, S., Sidek, S., \& Rahman, R. A. (2019). Prevalence and factors affecting food insecurity among university students in Pahang, Malaysia. Malaysian Journal of Nutrition, 25(1), 59-68. Retrieved from https://www.scopus.com/inward/record.uri?eid=2-s2.085072165925\&partnerlD=40\&md5=3f442900bc26f690b56b15f78f56bf82

Broton, K. M., Weaver, K. E., \& Mai, M. (2018). Hunger in higher education: Experiences and correlates of food insecurity among Wisconsin undergraduates from lowincome families. Social Sciences, 7(10). doi:10.3390/socsci7100179

Bruening, M., van Woerden, I., Todd, M., \& Laska, M. N. (2018). Hungry to learn: The prevalence and effects of food insecurity on health behaviors and outcomes over time among a diverse sample of university freshmen. International Journal of Behavioral Nutrition and Physical Activity, 15(1). doi:10.1186/s12966-018-0647-7

El Zein, A., Shelnutt, K. P., Colby, S., Vilaro, M. J., Zhou, W., Greene, G., .. Mathews, A. E. (2019). Prevalence and correlates of food insecurity among U.S. college students: A multi-institutional study. BMC Public Health, 19(1). doi:10.1186/s12889-019-6943-6

Ertz, M., \& Sarigollu, E. (2019). The behavior-attitude relationship and satisfaction in pro-environmental behavior. Environment and Behavior, 51(9-10), 1106-1132.

Feingold, B. J., Xue, X. B., Neff, R. A., Bozlak, C., Hosler, A. S., \& Jurkowski, J. M. (2019). Introducing a dynamic framework to jointly address policy impacts on environmental and human health in a regional produce recovery and redistribution system. Journal of Public Affairs, 19(3). doi:10.1002/pa.1859

Martinez, S. M., Grandner, M. A., Nazmi, A., Canedo, E. R., \& Ritchie, L. D. (2019). Pathways from food insecurity to health outcomes among California university students. Nutrients, 11(6). doi:10.3390/nu11061419

Ngarava, S., Zhou, L., Ayuk, J., \& Tatsvarei, S. (2019). Achieving Food Security in a Climate Change Environment: Considerations for Environmental Kuznets Curve Use in the South African Agricultural Sector. Climate, 7(9). doi:10.3390/cli7090108

Ramlee, I. S., Ali, A., Zalbahar, N., Wahab, R. A., \& Jaafar, S. N. (2019). Food insecurity among university students at two selected public Universities in Malaysia. Malaysian Applied Biology, 48(1), 101-110. Retrieved from https://www.scopus.com/record/display.uri?eid=2-s2.085064271623\&origin=inward\&txGid=129b7d32d763733e56a0bf0abf9b43df

Roggio, A. M. (2019). A systems thinking approach to the integration of food insecurity policy. Journal of Public Affairs, 19(3). doi:10.1002/pa.1862

Rush, E. (2019). Wicked problems: the challenge of food safety versus food security-working towards the SDG goals? European Journal of Clinical Nutrition, 73(8), 1091-1094. doi:10.1038/s41430-018-0352-2

Turner, L., Guthrie, J. F., \& Ralston, K. (2019). Community eligibility and other provisions for universal free meals at school: impact on student breakfast and lunch participation in California public schools. Translational behavioral medicine, 9(5), 931-941. doi:10.1093/tbm/ibz090

Ukegbu, P., Nwofia, B., Ndudiri, U., Uwakwe, N., \& Uwaegbute, A. (2019). Food Insecurity and Associated Factors Among University Students. Food and Nutrition Bulletin, 40(2), 271-281. doi:10.1177/0379572119826464

UN. (2016). \#Envision2030: 17 goals to transform the world for persons with disabilities. Retrieved from https://www.un.org/development/desa/disabilities/envision2030.html

Wooten, R., Spence, M., Colby, S., \& Steeves, E. A. (2019). Assessing food insecurity prevalence and associated factors among college students enrolled in a university in the Southeast USA. Public Health Nutrition, 22(3), 383-390. doi:10.1017/S1368980018003531 